\title{
Zinc Deficiency in Cirrhosis: Micronutrient for Thought?
}

\author{
Sasha Mangray ${ }^{1} \cdot$ Jamal Zweit $^{2} \cdot$ Puneet Puri $^{1}$
}

Received: 14 August 2015/Accepted: 18 August 2015/Published online: 30 August 2015

(C) Springer Science+Business Media New York 2015

Involved in several physiological processes related to human health, zinc $(\mathrm{Zn})$ is the second most abundant essential "trace" element. The actions of $\mathrm{Zn}$, mostly related to its catalytic or structural properties, also include serving as an enzymatic cofactor in the regulation of carbohydrate, fat, and protein metabolism. Though $\mathrm{Zn}$ is part of the important metalloenzyme copper- $\mathrm{Zn}$ superoxide dismutase, $\mathrm{Zn}$ can also alter oxidative stress [1, 2] and is also associated with innate and adaptive immune processes [3]. Zn also exhibits anti-apoptotic and anti-inflammatory effects: chronic ethanol exposure in an animal model induced $\mathrm{Zn}$ deficiency in the hepatic endoplasmic reticulum (ER) and in the mitochondria, which stressed these organelles in vitro, activating intrinsic cell death signaling pathways, and $\mathrm{Zn}$ supplementation protected against apoptosis [4]. In fact, ER and mitochondrial stress are present in advanced liver disease $[5,6]$. $\mathrm{Zn}$ is therefore of potential therapeutic value in this condition.

Zinc homeostasis following dietary intake is highly regulated, with body stores and tissue concentrations affected by intestinal absorption, gastrointestinal and urinary losses, and cellular retention. Dietary $\mathrm{Zn}$ is absorbed through enterocytes predominantly in the proximal small intestine. After enteric absorption, $\mathrm{Zn}$ enters a rapidly turning-over but small $(0.1 \%)$ plasma pool. It is then

Puneet Puri

ppuri@mcvh-vcu.edu

1 Division of Gastroenterology, Hepatology and Nutrition, Department of Internal Medicine, Virginia Commonwealth University School of Medicine, MCV Box 980341, Richmond, VA 23298-0341, USA

2 Division of Radiology, Section of Molecular Imaging, Virginia Commonwealth University School of Medicine, Richmond, VA, USA redistributed to tissues, which comprises the major $\mathrm{Zn}$ pool in the body. About $90 \%$ of body $\mathrm{Zn}$ is stored in skeletal muscle and bones, whereas $\sim 5 \%$ is stored in the liver. Net intestinal $\mathrm{Zn}$ absorption is essential for the homeostatic regulation of overall $\mathrm{Zn}$ status; dietary $\mathrm{Zn}$ intake activates adaptive mechanisms that maintain normal $\mathrm{Zn}$ status. Dietary factors can influence $\mathrm{Zn}$ bioavailability: in healthy individuals, feeding low-zinc diets increased zinc absorption via homeostatic mechanisms that upregulated zinc absorption and retention [7], confirming an earlier stable isotope based study [8].

The prevalence of $\mathrm{Zn}$ deficiency depends on underlying conditions. Diseases such as cirrhosis reportedly have a high prevalence of $\mathrm{Zn}$ deficiency [9]. Overt manifestations of $\mathrm{Zn}$ deficiency such as skin lesions, alopecia, hypogonadism, immune system dysfunction, and neurological disorders are often not present, are not easily recognized, or can be confounded by the presence of complications associated with underlying cirrhosis. Furthermore, alcoholics, including those that have developed cirrhosis, are a population at high risk of the development of $\mathrm{Zn}$ deficiency. Further, lower dietary zinc intake has been reported in alcoholics [9]. Interestingly in an animal model, alcohol use accompanying a $\mathrm{Zn}$-deficient diet was reported to synergistically increase hepatic lipid accumulation, inflammatory cell infiltration, oxidative stress, and expression of cell death receptors, accompanied by increased gut permeability and plasma endotoxin concentrations [10]. Human and animal studies have collectively established that $\mathrm{Zn}$ deficiency is associated with alcohol use and with cirrhosis [9].

In this issue of Digestive Diseases and Sciences, Sengupta et al. [11] highlight the importance of assessing zinc deficiency in a high-risk population. In this retrospective study, two thirds of the subjects had cirrhosis complicating hepatitis $\mathrm{C}$ infection and excessive alcohol intake. 
Moreover, $\mathrm{Zn}$ deficiency (serum $\mathrm{Zn}$ concentration $<0.66 \mu \mathrm{g} / \mathrm{mL}$ ) was more frequent in subjects with hepatitis C-related, cholestatic, or alcoholic liver disease when compared with other etiologies of cirrhosis, consistent with earlier observations cited by the authors. They also measured $\mathrm{Zn}$ deficiency in $83 \%$ of the subjects, more predominantly in decompensated cirrhotics; $91 \%$ of subjects classified as Child-Pugh class B, $94 \%$ classified as ChildPugh class C, and $95 \%$ of patients with Model for endstage liver disease (MELD scores) $>15$ had $\mathrm{Zn}$ deficiency. These findings support previous reports that $\mathrm{Zn}$ deficiency is remarkably prevalent in advanced liver disease.

In this study, Sengupta et al. further correlated $\mathrm{Zn}$ deficiency to complications of cirrhosis and to clinical outcomes. Using univariate and multivariate regression analysis, they reported that serum zinc concentrations inversely correlated with the presence of infection and ascites. While diuretic and lactulose use were significantly associated with decreased median $\mathrm{Zn}$ concentrations on univariate regression analysis; these findings, however, do not directly implicate low $\mathrm{Zn}$ concentrations in the occurrence of increased complications and should thus be interpreted cautiously. Infection can decrease serum zinc concentrations, making it appear spuriously low. The proposed mechanism of decreased serum zinc concentrations in infection is through $\mathrm{Zn}$ redistribution to tissues, mainly liver, which is mediated by transcriptional regulation of metallothionein [12-15]. This $\mathrm{Zn}$ redistribution is probably a cytoprotective host response mediated through $\mathrm{Zn}$-mediated regulation of intracellular redox balance [16]. Further, in an animal model of sepsis, $\mathrm{Zn}$ redistribution attenuated nuclear factor $\kappa$ light chain enhancer of activated $\mathrm{B}$ cells $(\mathrm{NF}-\kappa \mathrm{B})$ activation and inflammation [17]. It is therefore possible that the decreased serum $\mathrm{Zn}$ concentrations observed by Sengupta et al. may actually be an adaptive phenomenon.

The authors also correlated low serum $\mathrm{Zn}$ concentrations to low albumin concentrations and to ascites. In plasma, $80 \%$ of zinc is bound to the albumin. Also, serum albumin concentration is used in the calculation of the Child-Pugh score. In the present study, the authors reported mean and median albumin concentrations of $3.3 \mathrm{~g} / \mathrm{dL}$. Subjects with Child-Pugh classes B and $\mathrm{C}$ would thus have lower circulating albumin concentrations that would certainly confound measured serum $\mathrm{Zn}$ concentrations. Moreover, no formula is available to adjust $\mathrm{Zn}$ plasma concentrations for low serum albumin concentrations similar to those used to "correct" measured plasma calcium. Therefore, decreased serum Zn concentrations, as observed by Sengupta et al., should be carefully interpreted in the presence of hypoalbuminemia. Moreover, the presence of ascites indicates increased total body volume which could dilute serum $\mathrm{Zn}$ concentrations, since hemodilution (as in pregnancy) can influence serum Zn concentrations [18]. No convincing data, however, exist to support this hypothesis in cirrhosis. Furthermore, lactulose-induced diarrhea and diuretics can increase gastrointestinal and urinary $\mathrm{Zn}$ losses, further worsening $\mathrm{Zn}$ deficiency. These issues merit attention while interpreting the observations made by Sengupta et al.

In this study, the authors also reported that $\mathrm{Zn}$ deficiency correlated with shorter transplant-free survival. The authors observed that $\mathrm{Zn}$-deficient subjects had a $77 \%$ transplantfree survival rate at 1 year versus $96 \%$ for non-deficient subjects and $51 \%$ at 3 years versus $74 \%$ for non-deficient subjects. These survival differences should again be viewed cautiously in light of the higher MELD score and Child-Pugh class observed in the Zn-deficient subjects. As noted earlier, $\mathrm{Zn}$ deficiency was exceedingly prevalent in subjects with MELD scores $>15$ and those with ChildPugh classes B and C, suggesting that transplant-free survival rates were directly influenced by disease severity itself.

The authors then addressed the response to $\mathrm{Zn}$ supplementation with initial daily doses of either $\mathrm{Zn}$ sulfate $220 \mathrm{mg}$ or $\mathrm{Zn}$ gluconate $50 \mu \mathrm{g} / \mathrm{day}$. They reported an improvement in median serum zinc concentrations from 0.49 to $0.60 \mu \mathrm{g} / \mathrm{mL}(p<0.001)$ in $31 \%$ of subjects with $\mathrm{Zn}$ supplementation. These results should be carefully interpreted for the following reasons: (a) only a third of study subjects had paired serum $\mathrm{Zn}$ measurements; (b) although median serum $\mathrm{Zn}$ values improved with supplementation, it was well below $\mathrm{Zn}$ deficiency levels $(<0.66 \mu \mathrm{g} / \mathrm{mL})$; (c) different $\mathrm{Zn}$ preparations and an asneeded dosing strategy limit adequate interpretation of the response to $\mathrm{Zn}$ supplementation; and (d) improved median $\mathrm{Zn}$ concentrations following supplementation had no significant correlation with changes in the MELD score. These observations pose more questions than providing answers. Which zinc preparation should be used, for how long, and how frequently to monitor the changes? What outcomes should be evaluated and what serum $\mathrm{Zn}$ concentration should be used as a response and for which outcomes?

Sengupta et al. further recommended that a select subset of cirrhosis patients (Child-Pugh classes B and C, MELD scores $>15$ ) should be screened for $\mathrm{Zn}$ deficiency based on its high prevalence, and its correlation with disease severity, infection, and shorter transplant-free survival. The authors also suggested that $\mathrm{Zn}$ can be used as a marker for predicting disease severity in cirrhosis. While it is reasonable to screen a subset of cirrhotics for Zn deficiency, there remain several caveats, some of which have already been stated above.

In cirrhosis, serum $\mathrm{Zn}$ measurement is less sensitive and specific marker for the diagnosis of $\mathrm{Zn}$ deficiency than in health. Also, the plasma $\mathrm{Zn}$ pool is only $0.1 \%$ of the total body pool, representing the rapid $\mathrm{Zn}$ homeostasis pool 
given rapid fluctuations in plasma concentrations including diurnal and dietary influences. Several confounding factors highlighted above including inflammation, the acute-phase reaction, and hypoalbuminemia may lower serum $\mathrm{Zn}$ concentrations. In some situations, tissue redistribution of $\mathrm{Zn}$ may actually represent an adaptive physiological response and not necessarily indicate $\mathrm{Zn}$ deficiency. Additionally, increased gut permeability, decreased intestinal $\mathrm{Zn}$ absorption, increased gastrointestinal and urinary losses, malnutrition, portosystemic shunts, and diminished hepatic $\mathrm{Zn}$ extraction also affect $\mathrm{Zn}$ status in cirrhotics, confounding interpretation of serum measurements. What further remains to be defined is whether current standard replacement dosing is adequate for patients with advanced cirrhosis. The route of administration also needs to be considered in cirrhosis where intestinal absorption and altered bioavailability due to changes in first-pass metabolism may be compromised. Future studies could include a comparison of the efficacy of enteral versus parenteral replacement therapy and of different $\mathrm{Zn}$ compounds, as well as different doses for replacement in this patient population. The impact of $\mathrm{Zn}$ repletion on complications of cirrhosis such as hepatic encephalopathy, and increased susceptibility to infections, and clinical outcomes such as transplant-free survival deserves attention.

In conclusion, $\mathrm{Zn}$ is integrally linked to macronutrient metabolism, immune function and protein structure in the body. Accurate identification of $\mathrm{Zn}$ deficiency assumes importance in this high-risk population of cirrhosis. There is a need to further investigate novel sensitive biomarkers of $\mathrm{Zn}$ deficiency, such as measurement of $\mathrm{Zn}$-activated gene transcription and signal transduction. Based on current evidence, $\mathrm{Zn}$ replacement is not expected to alter major outcomes of patients with cirrhosis. Nevertheless, correction of $\mathrm{Zn}$ deficiency can potentially influence the quality of life with improved symptoms including anorexia, diarrhea, rash, and muscle cramps. A potential for decreased infection risk and hepatic encephalopathy merits rigorous investigation.

In broader terms, our current understanding of the mechanisms responsible for managing $\mathrm{Zn}$ metabolism in the liver and other tissues, such as in the pancreas, prostate, and mammary gland, remains immature. Nonetheless, Znbased intervention strategies may complement currently available therapeutic approaches. Key avenues to explore in the future involve understanding the contribution of genetic alterations of $\mathrm{Zn}$ management proteins in the liver and other organs. Improving the understanding of how specific tissues regulate $\mathrm{Zn}$ transport and metabolism and elucidating the effects of nutrition, environmental factors, and aging on $\mathrm{Zn}$ homeostasis are key to improving human health and disease.

Funding Part of this work is supported by NIH Grant to PP (K23 AA021179).

\section{References}

1. Vallee BL, Falchuk KH. The biochemical basis of zinc physiology. Physiol Rev. 1993;31:532-546.

2. Zhou Z, Wang L, Song Z, Saari JT, McClain CJ, Kang YJ. Zinc supplementation prevents alcoholic liver injury in mice through attenuation of oxidative stress. Am J Pathol. 2005;166:1681-1690.

3. Bonaventura P, Benedetti G, Albarède F, Miossec P. Zinc and its role in immunity and inflammation. Autoimmun Rev. 2015;14:277-285.

4. Sun Q, Zhong W, Zhang W, et al. Zinc deficiency mediates alcohol-induced apoptotic cell death in the liver of rats through activating ER and mitochondrial cell death pathways. Am J Physiol Gastrointest Liver Physiol. 2015;308:G757-G766.

5. Puri P, Mirshahi F, Cheung O, et al. Activation and dysregulation of the unfolded protein response in nonalcoholic fatty liver disease. Gastroenterology. 2008;134:568-576.

6. Malhi H, Kaufman RJ. Endoplasmic reticulum stress in liver disease. J Hepatol. 2011;54:795-809.

7. August D, Janghorbani M, Young VR. Determination of zinc and copper absorption at three dietary $\mathrm{Zn}-\mathrm{Cu}$ ratios by using stable isotope methods in young adult and elderly subjects. Am J Clin Nutr. 1989;50:1457-1463.

8. Wada L, Turnlund JR, King JC. Zinc utilization in young men fed adequate and low zinc intakes. J Nutr. 1985;115:1345-1354.

9. Mohammad MK, Zhou Z, Cave M, Barve A, McClain CJ. Zinc and liver disease. Nutr Clin Pract. 2012;27:8-20.

10. Zhong W, Zhao Y, Sun X, Song Z, McClain CJ, Zhou Z. Dietary zinc deficiency exaggerates ethanol-induced liver injury in mice: involvement of intrahepatic and extrahepatic factors. PLOS ONE. 2013;8:e76522.

11. Sengupta S, Wroblewski K, Aronsohn A, et al. Screening for zinc deficiency in patients with cirrhosis: When should we start? Dig Dis Sci. 2015. (Epub ahead of print). doi:10.1007/s10620-0153613-0.

12. Singh A, Smoak BL, Patterson KY, LeMay LG, Veillon C, Deuster PA. Biochemical indices of selected trace minerals in men: effect of stress. Am J Clin Nutr. 1991;53:126-131.

13. Schroeder JJ, Cousins RJ. Interleukin 6 regulates metallothionein gene expression and zinc metabolism in hepatocyte monolayer cultures. Proc Natl Acad Sci USA. 1990;87:3137-3141.

14. Cousins RJ, Leinart AS. Tissue-specific regulation of zinc metabolism and metallothionein genes by interleukin 1. FASEB J. 1988;2:2884-2890.

15. Liuzzi JP, Aydemir F, Nam H, Knutson MD, Cousins RJ. Zip14 (Slc39a14) mediates non-transferrin-bound iron uptake into cells. Proc Natl Acad Sci USA. 2006;103:13612-13617.

16. Oteiza PI. Zinc and the modulation of redox homeostasis. Free Radic Biol Med. 2012;53:1748-1759.

17. Bao S, Liu MJ, Lee B, Besecker B, Lai JP, et al. Zinc modulates the innate immune response in vivo to polymicrobial sepsis through regulation of NF-kappaB. Am J Physiol Lung Cell Mol Physiol. 2010;298:L744-L754.

18. Hobisch-Hagen P, Mörtl M, Schobersberger W. Hemostatic disorders in pregnancy and the peripartum period. Acta Anaesthesiol Scand Suppl. 1997;111:216-217. 